\title{
Electric Boiler and Heat Pump Thermo-Electrical Models for Demand Side Management Analysis in Low Voltage Grids
}

\author{
Iker Diaz de Cerio Mendaza*, Birgitte Bak-Jensen, Zhe Chen \\ Department of Energy Technology, Aalborg University, 9220 Aalborg, Denmark
}

\begin{abstract}
The last fifteen years many European countries have integrated large percentage of renewable energy on their electricity generation mix. In Denmark the $21.3 \%$ of the electricity consumed nowadays is produced by the wind, and it has planned to be the $50 \%$ by 2025 . In order to front future challenges on the power system control and operation, created by this unstable way of generation, Demand Side Management turns to be a promising solution.

The storage capacity from thermo-electric units, like electric boilers and heat pumps, allows operating them with certain freedom. Hence they can be employed under certain coordination, to actively respond to the power system fluctuations. The following paper presents two simple thermo-electrical models of an electrical boiler and an airsource $\mathrm{CO}_{2}$ heat pump system. The purpose is using them in low voltage grids analysis to assess their capacity and flexibility as active loads. The models were simulated under different Danish daily domestic hot water and space heating profiles. Results showed that under high heating demand conditions the flexibility of this kind of units may be drastically restricted due to their continuous operation.
\end{abstract}

Keywords: Electric boiler, heat pump, demand side management, low voltage grids, smart grids.

\section{Introduction}

The large development attained by the renewable energy in the last two decades, has awaked in many countries an interest in this alternative way of energy generation. At European level most countries through to different extent, have planned to increase the percentage of energy produced by green sources in the coming years. Clear example of this is Germany, who announced the intention of shutting down the nuclear reactors by 2022 and replacing them with more environmentally friendly energy technology [1].

Concerning wind power, Denmark is another interesting case to be mentioned. In 2010 , the $21.3 \%$ of the electricity consumed in the country proceeded from the wind [2], becoming a worldwide reference in terms of wind energy integration. In order to boost this tendency further on, the Danish Energy Authority set an ambitious target in 2007: 50\% of the electricity consumption in 2025 has to be supplied only by wind power [3]. Even though it offers significant advantages from an environmental and energetic independency point of view, this framework threatens to be very challenging in regards the control and operation of the actual power system.

The intermittent, variable and unpredictable nature of the renewable sources results in a non-stable generation. This might create power peaks exceeding the moment demand or imbalances due to a deficit in power supply. In January 2005, a storm hit Denmark causing a drop of the wind power production from over $2 \mathrm{GW}$ to less than a tenth over a period of eight hours [4].

One of the possible solutions to front these difficulties is having a flexible demand that can easily adapted and quickly respond to the power fluctuations suddenly produced in the system. Demand Side

\footnotetext{
* Manuscript received June 16, 2012; revised August 10, 2012.

Corresponding author. Tel.: +45 2037 8320; fax: +45 981-514-411; E-mail address: idm@et.aau.dk.
} 
Management (DSM) techniques were already exploited before with the purpose of allowing the power system to have an extra degree of freedom. After the First World War controlled Electric Boilers (EB) were introduced in Canada to take advantage of the surplus from the hydroelectric power [5].

The capacity of different loads to act actively in regards the power system stability was analysed before. Daryanian et al. investigated the utilization of EBs under Real Time Price (RTP) signals to allow the consumer changing his electricity usage habits, and in this way smoothing the power peaks in the power system [6].

Pedersen et al. [7] studied how floor heating systems, using heat pumps (HP), can support the power system balance. Considering the large time constant of this kind of heating systems an optimization method was presented to shift power demand, without comfort loss for the user, to hours with large wind power production. The load flexibility potential from an air source HP was experimentally analysed by Akmal et al. [8] with the same objectives. Reductions in the power system operation cost and decrease in the conventional power plant start-ups (due to sudden wind power curtailment) were stated advantages from demand shape modification.

The concept of flexible consumer inside a smart grid was evaluated by Halvgaard et al. [9]. An Economic Model Predictive Control (MPC) was used to command HP-floor heating systems and shifting their electricity consumption to periods where the energy prices were low. A part from the benefits provided to the grid, savings (25-33\%) in the electricity cost resulted from applying the operating strategy proposed.

The consequences of introducing HPs and EBs in North European power system with large share of wind power were assessed by Meibom et al. [10]. Aside from the environmental advantages (fuel saving due to oil burner's replacement), a higher wind power acknowledgement was cited from the EBs and HPs integration, due to the power regulation price reductions and the low price hours drop.

Seeing the importance that DSM is acquiring in the renewable energy integration, this paper introduces two thermo-electrical models of an EB and an air-source $\mathrm{CO}_{2} \mathrm{HP}$ system. The aim is using them to analyse their flexibility advantages in low voltage grids.

\begin{tabular}{|c|c|c|c|}
\hline \multicolumn{2}{|c|}{ Nomenclature } & \multicolumn{2}{|c|}{ Subscripts } \\
\hline A & $\operatorname{area}\left(\mathrm{m}^{2}\right)$ & $\mathrm{amb}$ & ambient \\
\hline COP & coefficient of performance (-) & aux & auxiliary (fan, pumps ...) \\
\hline $\mathrm{Cp}$ & specific heat capacity $\left(\mathrm{kJ} / \mathrm{kg} .{ }^{\circ} \mathrm{C}\right)$ & $\mathrm{c}$ & demand \\
\hline $\mathrm{D}$ & compressor bore $(\mathrm{m})$ & com & compressor \\
\hline $\mathrm{h}$ & enthalpy $(\mathrm{kJ} / \mathrm{kg})$ & $\mathrm{CO}_{2}$ & carbon dioxide \\
\hline J & moment of inertia $\left(\mathrm{kg} / \mathrm{m}^{2}\right)$ & $\mathrm{cW}$ & city water \\
\hline $\mathrm{L}$ & compressor stroke $(\mathrm{m})$ & $\mathrm{e}$ & electrical supply \\
\hline LMTD & log mean temperature difference $(-)$ & $\mathrm{EV}$ & evaporator \\
\hline & mass flow rate $(1 / s)$ & fsh & from space heating \\
\hline$n$ & number of cylinders (-) & $\mathrm{GC}$ & gas cooler \\
\hline $\mathrm{p}$ & pressure (MPa) & $\mathrm{H} 2 \mathrm{O}$ & water \\
\hline P & power $(\mathrm{W})$ & inside & inside the storage tank \\
\hline$Q$ & heat $(\mathrm{kJ})$ & IHX & internal heat exchanger \\
\hline Q & reactive power (VAr) & iso & isentropic \\
\hline $\mathrm{T}$ & temperature $\left({ }^{\circ} \mathrm{C}\right)$ & loss & storage tank losses \\
\hline UA & global heat exchange coefficient. $\left(\mathrm{W} /{ }^{\circ} \mathrm{C}\right)$ & $\mathrm{m}$ & mechanical \\
\hline V & volume (l) & $\mathrm{mi}$ & middle point between nodes \\
\hline $\mathrm{w}$ & compressor speed (rpm) & ni & node $\mathrm{i}$ of the tank \\
\hline $\mathrm{X}$ & control signal (-) & room & system installed room \\
\hline $\mathrm{z}$ & node high $(\mathrm{m})$ & $\begin{array}{l}\mathrm{s} \\
\mathrm{sh}\end{array}$ & $\begin{array}{l}\text { compressor displacement } \\
\text { to space heating }\end{array}$ \\
\hline \multicolumn{2}{|c|}{ Greek letters } & $\mathrm{t}$ & water storage tank \\
\hline$\delta$ & definition parameter $(-)$ & TIHX & tank immersed coil \\
\hline$\eta$ & efficiency $(-)$ & tot & total \\
\hline $\begin{array}{l}\pi \\
\lambda\end{array}$ & effective heat conductivity $\left(\mathrm{W} / \mathrm{m} .{ }^{\circ} \mathrm{C}\right)$ & vol & volumetric \\
\hline & & win & gas cooler inlet water \\
\hline & $\begin{array}{l}\text { density }(\mathrm{kg} / \mathrm{l}) \\
\text { torque }(\mathrm{N} . \mathrm{m})\end{array}$ & wout & gas cooler outlet water \\
\hline & & $1,2 \ldots 6$ & carbon dioxide state conditions \\
\hline
\end{tabular}




\section{Thermo-Electrical Models}

\subsection{Electric boiler}

Via water immersed resistor/electrode the EB uses electric energy as heat source to heat water. The model developed is oriented to a medium size family living in small house/apartment and its function is to heat water for the daily live activities (cleaning, cooking...). Fig.1 shows the model lay-out.

Table 1. EB Model Characteristics

\begin{tabular}{ll}
\hline Parameter & Value \\
\hline Tank volume $\left(\mathrm{V}_{\mathrm{t}}\right)$ & $160 \mathrm{l}$ \\
Power supply $\left(\mathrm{P}_{\mathrm{e}}\right)$ & $2400 \mathrm{~W}$ \\
Voltage level & $1 \mathrm{ph} 230 \mathrm{~V} / 50 \mathrm{~Hz}$ \\
Heat exchange coefficient $\left(\mathrm{UA}_{\text {loss }}\right)$ & $1\left(\mathrm{~W} /{ }^{\circ} \mathrm{C}\right)$ \\
City water temperature $\left(\mathrm{T}_{\mathrm{cw}}\right)$ & $9\left({ }^{\circ} \mathrm{C}\right)$ \\
Room temperature $\left(\mathrm{T}_{\text {room }}\right)$ & $15\left({ }^{\circ} \mathrm{C}\right)$ \\
On/Off control & $\mathrm{On}(\mathrm{X}=1) / \mathrm{Off}(\mathrm{X}=0)$ \\
\hline
\end{tabular}

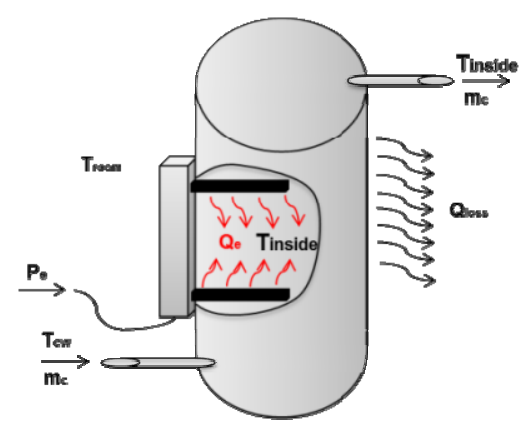

Fig.1. EB lay-out

As the tank size considered is relatively small the stratification effect was assumed depreciable. One node or fully mixed tank way was the option chose for the thermal modelling. The physical equations governing the system are based in the first law of thermodynamics.

$$
\rho_{\mathrm{H} 2 \mathrm{O}} V_{t} \frac{d T_{\text {inside }}}{d t}=Q_{e} X-m_{c} C p_{\mathrm{H} 2 \mathrm{O}}\left(T_{\text {inside }}-T_{c w}\right)-U A_{\text {loss }}\left(T_{\text {inside }}-T_{\text {room }}\right)
$$

\subsection{Heat pump system}

The system modelled is composed by an air-source transcritical $\mathrm{CO}_{2} \mathrm{HP}$, a large capacity storage tank and the DHW and space heating (SH) circuit's (fig.2 (a)). Two simple techniques are used to control it, an on/off to define the moment when HP energy supply is required and compressor speed control for applying water at constant temperature of $80^{\circ} \mathrm{C}$ to the tank.

\subsubsection{Transcritical $\mathrm{CO} 2$ heat pump}

A HP is the combination of different electro and thermo-mechanical elements which define a thermodynamical cycle. It aims transferring thermal energy from one source at lower/higher temperature to another location at higher/lower temperature depending on the working mode, i.e. heating or cooling.

The environmental advantages and the good performance from the transcritical cycles justify the election of $\mathrm{CO}_{2}$ as refrigerant for the presented model. The $\mathrm{CO}_{2}$ thermodynamic properties were obtained from the National Institute of Standards and Technology (NIST) online-data base [11]. From this, look-up tables were created in Matlab/Simulink to define the Lorentz cycle states and represent the consecutive changes experienced by the working fluid (Fig.2 (b)).

The overall model consist of the evaporator (E), internal heat exchanger (IHX), compressor (C), gas cooler (GC) and expansion valve (EV) sub-models. Besides the following assumptions were considered:

- Negligible heat losses with ambient.

- Water is always in liquid phase during the heat transfer process in the gas cooler.

- Not pressure drops in the $\mathrm{CO}_{2}$ circuit either in the water one.

- Evaporation process is ideal and the output conditions are saturated.

- The compression is adiabatic but not isentropic. 


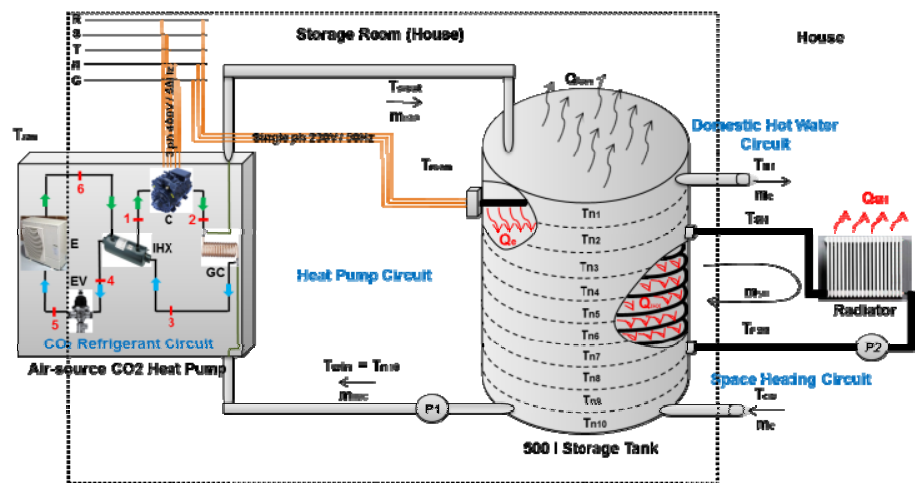

(a)

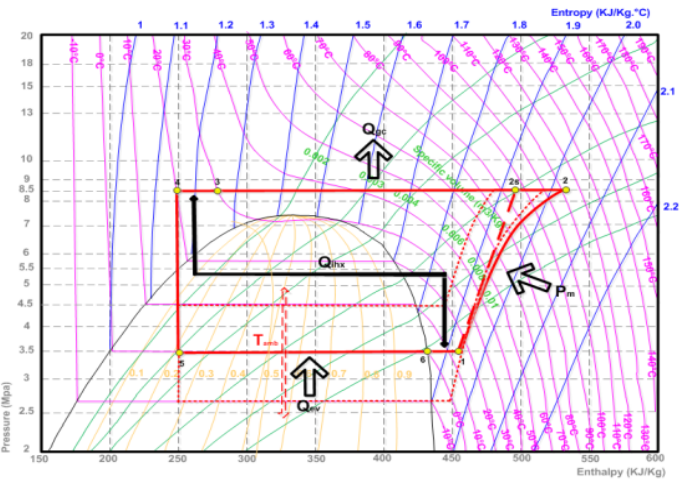

(b)

Fig. 2. (a) HP System, (b) Lorentz cycle.

\subsubsection{Evaporator}

As it is assumed an ideal evaporator, the temperature output of the refrigerant $\left(T_{6}\right)$ is equal to the atmospheric one. Thus, the low pressure line of the cycle is determinate by the ambient conditions using the NIST data. The process is considered to be isobaric.

$$
T_{a m b}=T_{6}
$$

\subsubsection{Reciprocating compressor}

A Dorin single stage $\mathrm{CO}_{2}$ compressor with the same characteristics given in [12] was chosen as a subject. From the displacement expression $\left(\mathrm{V}_{\mathrm{S}}\right)$ the refrigerant mass flow rate was calculated as:

$$
\begin{aligned}
& V_{s}=n D^{2} L\left(\frac{\pi}{4}\right) \\
& m_{\mathrm{CO}_{2}}=\rho \eta_{\text {vol }} V_{s}\left(\frac{w}{60}\right)
\end{aligned}
$$

The following volumetric and isentropic efficiency correlations developed for the mentioned compressor were used to determine the compression process quality [12].

$$
\begin{aligned}
& \eta_{\text {vol }}=1.1636-0.2188\left(\frac{p_{2}}{p_{1}}\right)+0.0163\left(\frac{p_{2}}{p_{1}}\right)^{2} \\
& \eta_{\text {iso }}=0.61+0.0356\left(\frac{p_{2}}{p_{1}}\right)-0.0257\left(\frac{p_{2}}{p_{1}}\right)^{2}+0.0022\left(\frac{p_{2}}{p_{1}}\right)^{3}
\end{aligned}
$$

The optimum discharge pressure expression developed by Sarkar [12] was utilized to define the high pressure line of the cycle depending on the evaporation and the gas cooler output temperature conditions. The mechanical power required by the compressor was obtained from the following equation:

$$
\begin{aligned}
& P_{2, o p t}=3.47+0.32 T_{E V}+2.23 T_{3}-0.0134 T_{E V} T_{3}+3.7 \times 10^{-3} T_{3}^{2} \\
& P_{m}=m_{C O_{2}}\left(h_{2}-h_{1}\right) \frac{1}{\eta_{m}}
\end{aligned}
$$

\subsubsection{Internal heat exchanger}

According to the pressure conditions set by the evaporation process, the refrigerant output temperature 
conditions in the subcritical and supercritical side of the IHX were calculated using the LMTD method using the expressions developed by Stoecker [13]. For this reason it was assumed constant heat capacity of the working fluid it the process, being determinate by the inlet pressure and temperature conditions.

$$
\begin{aligned}
& \text { Subcritical side: } T_{1}=T_{6}-\left(T_{6}-T_{3}\right) \frac{\left(1-\exp \left[\frac{U A_{I H X}}{m_{C O_{2}}}\left(\frac{1}{C p_{6}}-\frac{1}{C p_{3}}\right)\right]\right)}{\left(\frac{C p_{6}}{C p_{3}}-\exp \left[\frac{U A_{I H X}}{m_{C O_{2}}}\left(\frac{1}{C p_{6}}-\frac{1}{C p_{3}}\right)\right]\right)} \\
& \text { Supercritical side: } T_{4}=T_{3}-\left(T_{3}-T_{4}\right) \frac{\left(1-\exp \left[\frac{U A_{I H X}}{m_{C O_{2}}}\left(\frac{1}{C p_{3}}-\frac{1}{C p_{6}}\right)\right]\right)}{\left(\frac{C p_{3}}{C p_{6}}-\exp \left[\frac{U A_{I H X}}{m_{C O_{2}}}\left(\frac{1}{C p_{3}}-\frac{1}{C p_{6}}\right)\right]\right)}
\end{aligned}
$$

Due to the specific heat capacity behaviour of the $\mathrm{CO}_{2}$ in the supercritical zone $[12,14]$, look-up tables based in NIST data were created again to estimate its value in every state.

\subsubsection{Gas cooler}

The same assumptions and methodology was considered in the $\mathrm{GC}$ to determine the $\mathrm{CO}_{2}$ and the water outlet temperature [13]. As the water is taken from bottom of the tank $T_{w i n}=T_{n 10}$.

$$
\begin{aligned}
& T_{3}=T_{2}-\left(T_{2}-T_{n 10}\right) \frac{\left(1-\exp \left[U A_{G C}\left(\frac{1}{m_{\mathrm{CO}_{2}} C p_{2}}-\frac{1}{m_{\mathrm{H} 2 \mathrm{O}} C p_{\mathrm{H} 2 \mathrm{O}}}\right)\right]\right)}{\left(\frac{m_{\mathrm{CO}_{2}} C p_{2}}{m_{\mathrm{H} 2 \mathrm{O}} C p_{\mathrm{H} 2 \mathrm{O}}}-\exp \left[U A_{G \mathrm{C}}\left(\frac{1}{m_{\mathrm{CO}_{2}} C p_{2}}-\frac{1}{m_{\mathrm{H} 2 \mathrm{O}} C p_{\mathrm{H} 2 \mathrm{O}}}\right)\right]\right)} \\
& T_{\text {wout }}=T_{\text {win }}+\frac{m_{\mathrm{CO}_{2}}\left(h_{3}-h_{2}\right)}{m_{\mathrm{H} 2 \mathrm{O}} \mathrm{CP} p_{\mathrm{H} 2 \mathrm{O}}}
\end{aligned}
$$

\subsubsection{Expansion valve}

The expansion process was assumed isenthalpic considering negligible any surrounding heat losses.

$$
h_{4}=h_{5}
$$

\subsubsection{AC induction motor}

A first order equation representing the drive motion was used to model the dynamics of the machine [15]. Due to the simulation length no friction losses were considered, defining the mechanical torque as:

$$
\begin{aligned}
& J \frac{d w}{d t}=\tau_{e}-\tau_{m} \\
& \tau_{m}=\frac{P_{m}}{w}
\end{aligned}
$$

\subsubsection{Storage tank and space heating circuit}

The key point of the EB and HP systems from a DSM approach is the storage tank. It can be seen as an inter-phase among the electrical consumption and the DHW/SH demand, which allows certain operation independency separating both moments. In this case the stratification phenomenon in the storage tank was 
modelled in order to have more realistic approach of the system behaviour. The tank was divided into 10 layers creating an energy balance in each of them as the author [16] proposed:

$$
\begin{aligned}
& \rho_{H 2 O} V_{n i} C p_{H 20} \frac{d T_{n i}}{d t}=\delta_{n i}^{H P} m_{H 20} C p_{H 20}\left(T_{\text {wout }}-T_{n i}\right)-\delta_{n i}^{c} m_{H 20} C p_{H 20}\left(T_{n i}-T_{c w}\right)-U_{\text {loss }} A_{n i}\left(T_{n i}-T_{\text {room }}\right) \\
& +\delta_{n i}^{+} m_{c} C p_{H 20}\left(T_{n i-1}-T_{n i}\right)+\delta_{n i}^{-} m_{c} C p_{H 20}\left(T_{n i}-T_{n i+1}\right)+A_{n i} \frac{\lambda_{e}}{Z_{n i}}\left(T_{n i+1}-2 T_{n i}+T_{n i-1}\right)+Q_{e}-\delta_{m i} Q_{m i}
\end{aligned}
$$

The fluid circulating through the space heating circuit is heated through a heat exchanger coil immersed in the tank. In each layer where a part of the coil is present (nodes from $n 3$ to $n 8$ ), $Q_{\text {mi }}$ will be active representing the heat provided by the stored water in that layer to the part of the coil immersed in it $\left(\delta_{m i}=1\right.$ for $3 \leq i \leq 8$, rest 0$)$.

$$
Q_{m i}=m_{s h} C p_{H 20}\left(T_{m i}-T_{m i-1}\right)
$$

The coil has been divided in six subsections (Fig. 3(a)). For every one the output temperature was calculated as (for $i=3, T_{m i}=T_{\text {sh }}$ and $\mathrm{i}=8, T_{m i-1}=T_{\text {fsh }}$ ):

$$
\begin{aligned}
& T_{m i}=T_{n i}+\left(T_{m i-1}-T_{n i}\right) \times \exp \left[-\frac{U A_{T H X X}}{m_{s h} C p_{H 2 O}}\right] \\
& Q_{s h}=m_{s h} C p_{H 20}\left(T_{s h}-T_{\text {ssh }}\right)
\end{aligned}
$$

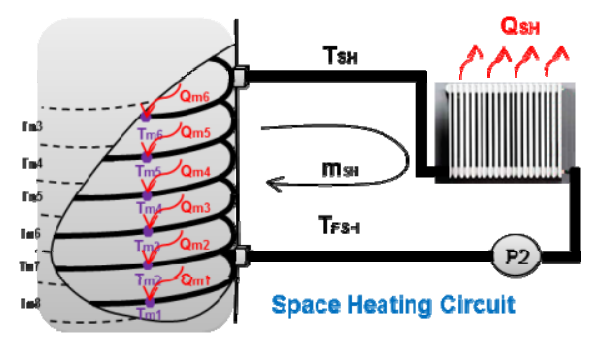

(a)

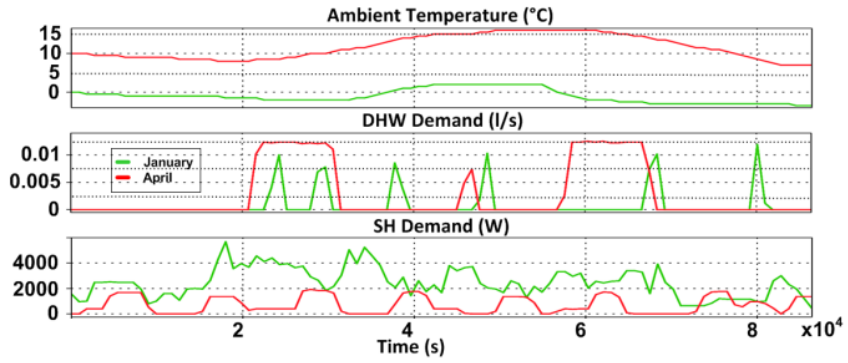

(b)

Fig.3. (a) Space heating circuit lay-out, (b) Temperature, SH and DHW profiles

\section{System Analysis}

Domestic energy consumption and its pattern are features strongly varying from family to family depending on the single habits. The energy consumption for an average household in Denmark is around $15000 \mathrm{KWh} /$ year from where $2700 \mathrm{KWh}$ has DHW purposes.

For the following analysis Electrical, SH, and DHW energy consumption data from 25 houses, located in the island of Fyn (Denmark), was used [17]. Rather than creating an average profiles from them, authors found more interesting taking a representative house as a subject and analyse it. Fig.3 (b) shows the mentioned profiles for a singular day in January and April.

\section{Results and Discussion}

Since the function of the EB was heating water for daily activities of a medium size families living in flat/apartment with additional space heating source (district heating) the model was only studied under DHW demand conditions. The HP system instead was intended to supply both types of thermal demand. 


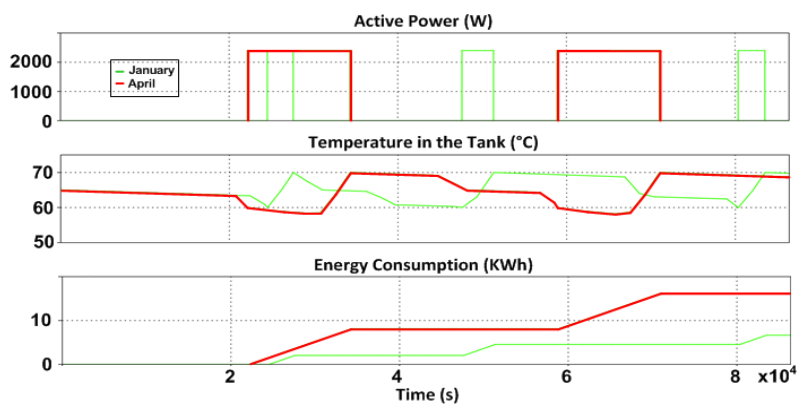

Fig.4.EB simulated behaviour.

Fig. 4 shows the differences in electrical consumption depending on the hot water mass flow demanded in the EB. Due to an overconsumption and the sub-dimensioned tank capacity the temperatures decreases below the permitted limits in the month of April.

In the HP system model operation differences were observed from one month to other. Fig. 5 shows that frequent start-ups and over-operation capacity was required in January with the purpose of keeping HP water output temperature and the temperature inside tank within certain limits. This fact may restrict, in certain moments, the capacity of these units to respond actively; having direct consequences in the DSM strategy efficiency.

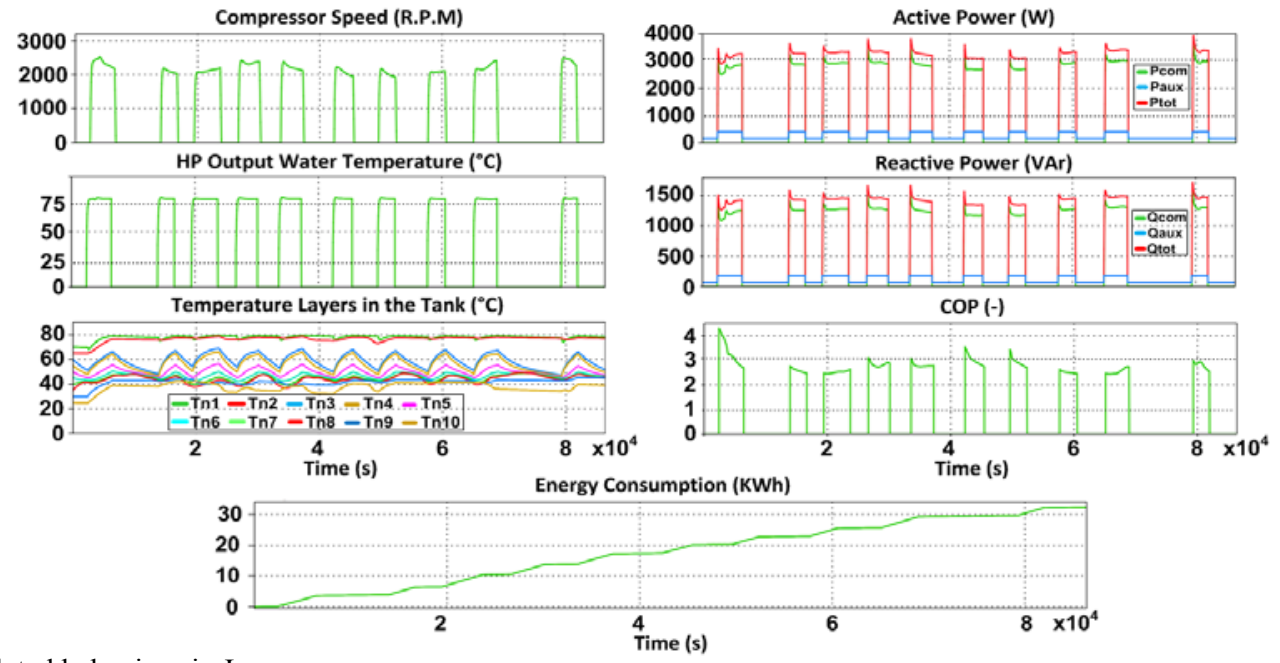

Fig.5.HP simulated behaviour in January.

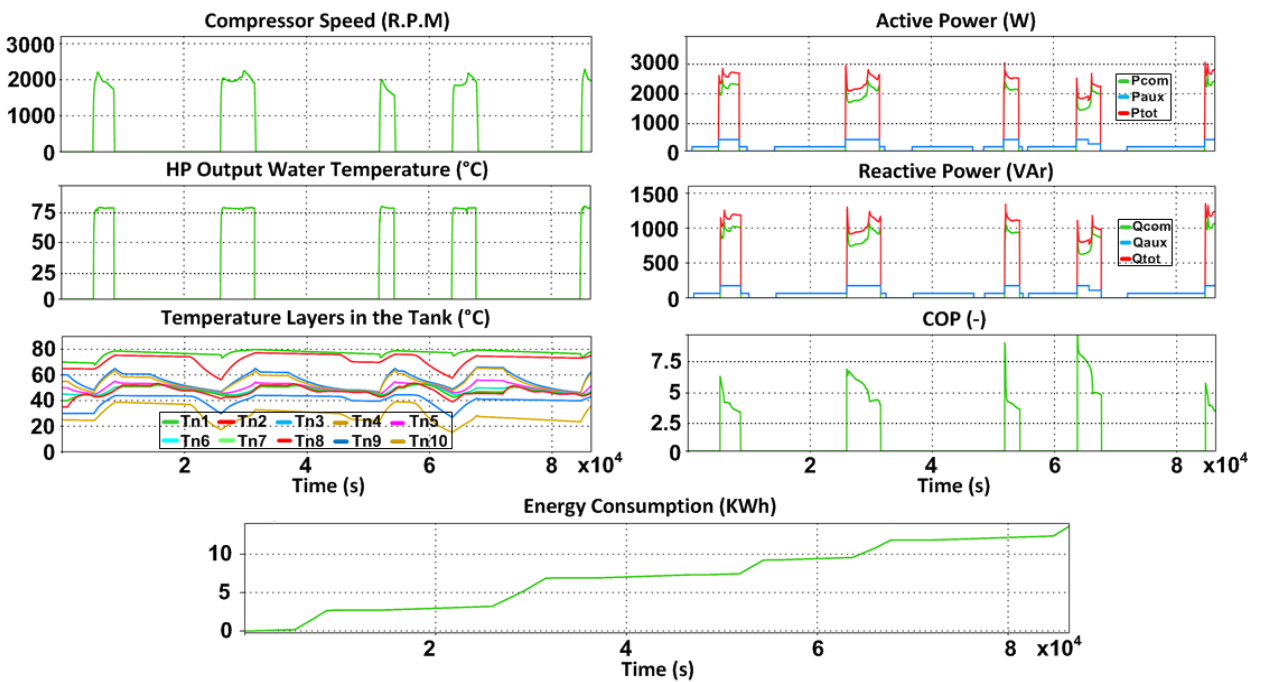

Fig. 6. HP simulated behaviour in April. 
In this kind of systems, where HP unit is connected directly to the upper and lower part of the storage tank, it can be notice that the COP is very much affected by the temperature in the bottom of the tank. As the GC is cooled with water coming from low part of the tank, the higher the temperature is the lower the COP will be. This is more and more notable the longer the HP is in operation.

During months with lower energy consumption the flexibility offered by these units can be higher. From Fig. 6 can be notice a reduction of start-ups number and a higher COPs achievement in comparison with the previous scenario. The reason for this last state is the atmospheric temperature increase and the low temperature conditions given in the bottom layer of the tank. In this context a correct sizing of the thermal storage acquires notable importance, since the operation way and the power consumed by this kind of systems will be directly affected. Hence for future participation in DSM strategies, these units should be dimensioned in concordance with the demand they have to supply and the possible future services they may be requested for.

\section{Conclusion}

In the present paper two simple thermo-electrical models of EB and CO2 HP has been introduced to be used in demand side management studies and low voltage grids analysis. Two different energy demand scenarios were simulated observing that in high energy consumption conditions the capacity to act as flexible loads of these units may be drastically reduced due to their continuous operation.

\section{Acknowledgement}

The authors would like to thank the Danish Council for Strategic Research for providing the financial support for the project "Development of a Secure, Economic and Environmentally-friendly Modern Power Systems" (DSF 09-067255).

\section{References}

[1] Knopf B, Kondziella H, Pahle M, Götz M, Bruckner T. Edenhofer O. Scenarios for phasing out nuclear energy in Germany. Research report. Friedrich-Ebert-Stiftung, 2011.

[2] Pobłocka A, Brückmann A, Piria R, Frank R, Bauknecht D. Integration of electricity from renewables to the electricity grid and to the electricity market-RES-INTEGRATION. Research report. Eclareon and Öko-Institut, 2011.

[3] A visionary Danish energy policy 2025. Research report. Danish Energy Agency, 2007.

[4] 50\% wind power in Denmark in 2025. Research report. Ea Energy Analyses, 2007.

[5] Eaton M. Automatic operation of electric boilers. Transactions of the American Institute of Electrical Engineers, 1947; 66(1):1061-1069.

[6] Daryanian B, Bohn RE, Tabors RD. Control of electric thermal storage under real time pricing. In: Proc. of Advances in Power System Control, Operation and Management, 1991:397-403.

[7] Pedersen TS, Andersen P, Nielsen KM, Starmose HL, Pedersen PD. Using heat pump energy storages in the power grid. In: Proc. of IEEE International Conference on Control Applications (CCA), 2011:1106-1111.

[8] Akmal M, Flynn D, Kennedy J, Fox B. Flexible heat load for managing wind variability in the Irish power system. In: Proceedings of the 44th International Universities Power Engineering Conference (UPEC), 2009:1-5.

[9] Halvgaard R, Poulsen NK, Madsen H, Jørgensen JB. Economic model predictive control for building climate control in a smart grid. In: IEEE PES Innovative Smart Grid Technologies (ISGT). 2012:1-6.

[10] Meibom P, Kiviluoma J, Barth R, Brand H, Weber C, Larsen H. Value of electrical heat boilers and heat pumps for wind power integration. Wind Energy, 2007; 10(4):321-337.

[11] National Institute of Standards and Technology (NIST). US Department of Commerce. [Online] Available: http://webbook.nist.gov/.

[12] Sarkar J. Transcritical carbon dioxide heat pumps for simultaneous cooling and heating. PhD dissertation. Indian Institute of Technology. Kharagpur, India; 2005.

[13] Stoecker WF. Design of Thermal Systems. 3rd ed. New York: McGraw-Hill; 1989.

[14] Stene J. Residential $\mathrm{CO}_{2}$ Heat pump system for combined space heating and hot water heating. PhD dissertation. Norwegian University of Science and Technology (NTNU). Trondheim, Norway; 2004.

[15] Ahmad M. High Performance AC Drives: Modelling Analysis and Control (Power Systems). 1st ed. New York: Springer; 2010.

[16] Eicker U. Solar Technologies for Buildings. 1st ed. San Francisco: Wiley; 2003.

[17] Korsgaard AR. Design and control of household CHP fuel cell system. PhD dissertation. Aalborg University. 2006. 